\title{
Potential factors that may promote successful cognitive aging
}

This article was published in the following Dove Press journal:

Nursing: Research and Reviews

19 June 2012

Number of times this article has been viewed

\section{David E Vance}

Center for Nursing Research, School of Nursing, Edward R Roybal Center for Translational Research in Aging and Mobility, University of Alabama at Birmingham (UAB), Birmingham, AL, USA
Correspondence: David E Vance

Center for Nursing Research, School of Nursing, Room I019F, I70I University Boulevard, and Edward R Roybal Center for Translational Research in Aging and Mobility, University of Alabama at Birmingham (UAB), Birmingham,

AL 35294-I2 I0, USA

Tel +I 2059347589

Fax +l 2059967183

Email devance@uab.edu
Abstract: With the unprecedented number of older adults worldwide, it is important to consider ways of facilitating successful cognitive aging. One way to think of this is by augmenting or bolstering cognitive reserve. Loosely defined, cognitive reserve is considered a neurological reservoir that can be depleted by physiological insults (eg, white matter hyperintensities, oxidative stress) to the brain but yet maintain optimal cognitive functioning. Cognitive reserve is built up or depleted by processes of positive and negative neuroplasticity, respectively. Lifestyle factors such as physical exercise $(+)$, mental stimulation $(+)$, good sleep hygiene $(+)$, substance abuse $(-)$, sedentary lifestyle $(-)$, chronic stress and depression $(-)$, social isolation $(-)$, and poor health $(-)$ can either promote or discourage positive and negative neuroplasticity, which in turn impacts cognitive reserve. Nurses are encouraged to understand these processes so they can help facilitate successful cognitive aging in their patients.

Keywords: cognitive reserve, Alzheimer's disease, neuroplasticity

\section{Introduction}

In the 1990s, the Decade of the Brain came and went and with advances in technology such as magnet resonance imaging (MRI) ushered in a new understanding of the mechanisms involved with cognitive health. In 2010, the Decade of Behavior ended. Research from both decades has galvanized much of what we know about the interaction between behavior and cognitive health. We now recognize that neurological function and cognitive ability are not static processes but dynamic and reliant on many behaviors including lifestyle and health choices, mental stimulation and intellectual pursuits, and cognitive exercise just to name a few. This interaction between behavior and brain health becomes especially relevant for nurses who are providing care for increasing numbers of older adults.

With advancing years, age-related cognitive loss becomes more apparent. In a large sample of community-dwelling older adults 65 years plus, $26 \%$ indicated experiencing subjective memory loss. ${ }^{1}$ Such self-reported cognitive problems often correspond to objective measures of cognitive functioning. ${ }^{2}$ For example, in a sample of communitydwelling older (70+ years) adults without dementia, Low and colleagues used a battery of cognitive measures and found that nearly one-third (33.3\%) of the sample were classified as having 'cognitive impairment no dementia'. ${ }^{3}$ Such non-pathological age-related cognitive changes are a normal part of the aging process; however, when the cognitive changes are more pronounced and severe, this may reflect pathological aging as observed with dementias such as Alzheimer's disease. Still, such age-related 
cognitive loss can impair everyday functioning such as handling finances, successfully negotiating medication regimens, remembering medical appointments, and actively engaging in social activities, all of which impact health and quality of life. ${ }^{4}$

Despite the pervasiveness of such age-related cognitive declines, the interaction between behavior and brain health offers solutions to either remedy or mitigate such losses in cognitive functioning. Just as some people have more muscle reserve than others which is protective against agerelated sarcopenia, ${ }^{5}$ cognitive reserve is now recognized as a possible neurological reservoir that can sustain cognitive functioning after periods of illness and poor health, substance use, depression, ${ }^{6}$ and other insults such as white matter hyperintensities, ${ }^{7,8}$ oxidative stress and neuroinflammation, ${ }^{9-11}$ elevated cortisol levels, ${ }^{12}$ insulin resistance,${ }^{13}$ mitochondrial damage, ${ }^{14}$ over-activation of glutamate receptors, ${ }^{15}$ and decreased perfusion and cerebrovascularization ${ }^{16}$ known to gradually impair neurological functioning. Cognitive reserve, sometimes called brain reserve, generally refers to the sophistication of neuronal/dendritic connections from which information is transmitted and cognition/mentation emerges. ${ }^{17}$ The greater the strength and complexity of these connections, the more the brain can absorb damage before cognitive functioning is compromised..$^{18}$ Thus, it is generally argued that the more cognitive reserve one has, the more likely one is able to maintain optimal cognitive functioning despite a number of known neurological insults. ${ }^{17,19-21}$ However, despite a large number of studies that support the concept of cognitive reserve, ${ }^{22-24}$ other studies have found little or no support for it. ${ }^{25-28}$ Albeit, studying cognitive reserve is difficult because there are different methods of how it is measured (ie, cognitive changes over time; from a cross-sectional sample, subtracting a standardized measure of a fluid ability from a standardized measure of crystallized ability) and different assumptions of what affects it (ie, does the amount of education predict it or does the quality of that education matter?). So the reader should keep these methodological issues in mind when interpreting the results of studies examining cognitive reserve.

\section{Positive and negative neuroplasticity}

Cognitive reserve can be increased or decreased due to two complex, overarching processes - positive neuroplasticity and negative neuroplasticity. ${ }^{17}$ Positive neuroplasticity refers to the brain's ability to make more and stronger connections between neurons in response to exposure to novel stimulation. This process supports better cognitive functioning in general.
Likewise, negative neuroplasticity refers to the atrophy of such connections between neurons in response to low stimulation or physiological insults. ${ }^{29}$ These processes can be observed in a seminal, highly publicized study.

Boyke and colleagues ${ }^{30}$ recruited older adults (50-67 years old) and attempted to teach them to juggle with a 3-ball cascade pattern. They conducted MRI scans before learning to juggle, once juggling was learned, and then 3 months later after participants were instructed to stop juggling. Of those who learned to juggle ( 25 out of 69 older adults), the MRI revealed that from the initial scans to the scans when the older adults became proficient at juggling, gray matter growth was observed in the hippocampus and nucleus accumbens (these are brain structures responsible for memory function). This growth may reflect the process of positive neuroplasticity. Likewise, from the height of proficiency to 3 months later when participants were no longer juggling, shrinkage in the hippocampus and nucleus accumbens was detected. Stopping juggling and the subsequent shrinkage may reflect the process of negative neuroplasticity (albeit, this process is much more complex and is overly simplified here). The findings from this study show how behavior and environment, such as learning a new skill, may increase cognitive reserve while the atrophy of the skill can decrease cognitive reserve.

These findings highlight that cognitive function can be protected across the lifespan through processes referred to as positive and negative neuroplasticity which either expand or shrink cognitive reserve. ${ }^{6,17}$ In fact, a variety of studies show that being actively engaged in mentally stimulating leisure activities over one's life (eg, playing musical instruments, learning a second language, playing chess) is protective against cognitive declines with age ${ }^{23,31}$ which delay, but may not necessarily abate, the presentation of Alzheimer's disease and other dementias.

\section{Factors of cognitive reserve}

The cognitive and neuroscience literature indicates a variety of lifestyle factors that may encourage positive neuroplasticity which support cognitive reserve and thus cognitive functioning (Figure 1). Such factors include mental stimulation, ${ }^{32}$ cognitive leisure activities, ${ }^{19-21,33-36}$ social stimulation, ${ }^{37}$ a healthy diet rich in fish and antioxidants, ${ }^{38,39}$ good sleep hygiene, ${ }^{40}$ cognitive remediation, ${ }^{41}$ and physical activity; ${ }^{42-44}$ likewise, the absence of such positive factors promotes negative neuroplasticity. ${ }^{17,45}$ Landua and colleagues examined the association between lifetime cognitive engagement on $\beta$-amyloid (ie, the protein associated with Alzheimer's disease pathology) deposition in young adults, 


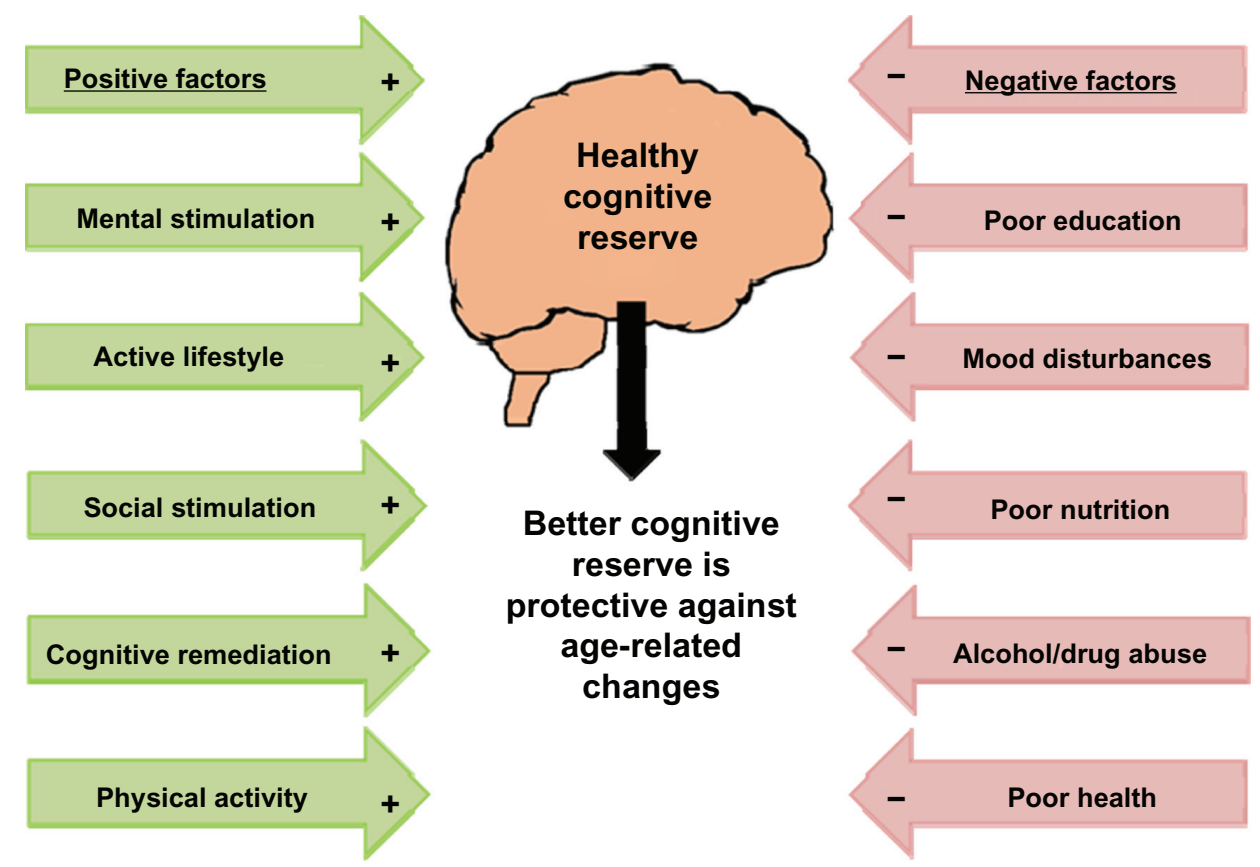

Figure I Contributing factors of cognitive reserve.

Notes: + contributes to positive neuroplasticity which supports cognitive reserve; - contributes to negative neuroplasticity which does not support cognitive reserve.

older adults, and older adults with Alzheimer's disease. ${ }^{46}$ These researchers found that those older adults with higher levels of lifetime cognitive engagement had less $\beta$-amyloid deposition compared to those with lower levels of lifetime cognitive engagement. Such cognitive engagement may actually slow the buildup of $\beta$-amyloid. However, it is also likely that engaging in cognitively stimulating activities is also related to being engaged in other healthy lifestyle factors (Figure 1) that have been shown to enhance physical health and thus, brain health.

However, Schweizer and colleagues measured cognitive engagement as bilingualism. ${ }^{24}$ Thus, it was hypothesized that those who were bilingual would have more cognitive reserve which could delay the symptoms of Alzheimer's disease; as such, the brains of bilinguals with Alzheimer's disease should show more brain atrophy compared to the brains of monolinguals who were matched on years of education and level of cognitive performance. Using computed tomography (CT) scans, these researchers found that indeed bilinguals possessed greater brain atrophy than monolinguals of the same cognitive level; this suggests that the sophisticated connections between existing neurons were still supporting cognitive functioning despite greater insult to the brain. Thus, it may be that cognitive engagement does not necessarily slow the buildup of $\beta$-amyloid but abates neuronal atrophy; instead, since neuronal pathways are enhanced in the frontal lobes (ie, brain areas responsible for executive functioning) by such cognitive engagement, this may compensate for when insults to the brain do occur. This finding corresponds to the executive functioning hypothesis which states that these specific cognitive abilities (ie, metacognition, reasoning, problem solving) within the frontal and parietal lobes directs the use of other cognitive abilities (ie, memory, attention, language) and that when executive functioning abilities are compromised, the other cognitive abilities are likewise compromised..$^{18}$ Regardless of how these lifestyle factors promote positive and negative neuroplasticity and cognitive reserve, obviously good health practices such as cognitive engagement, mental stimulation, proper nutrition, and exercise support the complex physiological underpinnings of neurological health which obviously support optimal cognitive functioning.

Different types of mental stimulation are also very important. In fact, several studies have found that loneliness was associated with the development of poorer cognitive functioning and Alzheimer's disease; this suggests interacting with others promotes cognitive reserve..$^{37,47,48}$ For example, in a sample of 823 older adults without dementia, Wilson and colleagues assessed participants on loneliness at baseline and followed them over 4 years. These researchers found that compared to those who were not lonely (ie, those in the 10th percentile), lonely participants (ie, those in the 90th percentile) had twice the risk of developing Alzheimer's disease. ${ }^{49}$ In studies such as this, those developing cognitive 
problems and Alzheimer's disease may naturally socially withdraw because being around others is too cognitively challenging and uncomfortable; therefore, this may account for this association between loneliness and deficits in cognition. ${ }^{50}$ In support of this alternative hypothesis, although Green and colleagues did find that the size of one's social network was predictive of better cognitive functioning in a cross-sectional analysis of older adults, this result was not found longitudinally. ${ }^{51}$ However, it is important to note that these studies are difficult to interpret because the quality of the social interactions (ie, the sophistication of the social exchange which may be the driving influence of neuroplasticity) of such networks is not easily measured. Yet, the prevailing consensus at the moment is that social stimulation is important for cognitive aging.

Research has also shown that cognitive remediation therapy can improve specific mental functions; usually such training focuses on improving a key mental ability such as visual speed of processing which is needed for safe driving and everyday functioning. ${ }^{52-54}$ In one study, Vance and colleagues recruited 159 community-dwelling older adults without dementia; nearly half of the sample were administered a specially designed, computer game program targeted to improve the speed in which they process visual information. After only 10 hours of training on this program, those older adults who were in the experimental condition displayed significant gains in the cognitive domain of visual speed of processing compared to controls. They also found these gains to be robust over a 2-year period, suggesting that even brief cognitive training can have significant impact years later. ${ }^{55}$ This particular training is important because it has been shown to improve driving ability and everyday functioning. ${ }^{56,57}$ Unfortunately, improvement in one cognitive domain for which training occurred (eg, visual speed of processing) usually does not automatically improve other cognitive abilities (eg, memory); in other words, there is usually not many transfer effects observed between cognitive domains. ${ }^{41,58}$ Therefore, it is important to select the right cognitive remediation therapy for improvement in a particular cognitive domain where deficits may be occurring. ${ }^{41,58}$ Also, it is important to keep in mind that although there are many cognitive remediation therapies available to the public, not all of them have been found to be effective in improving cognition. ${ }^{41,58}$ However, such studies on cognitive remediation therapy are usually limited to improving a specific mental function (ie, visual speed of processing) compared to overall global cognitive improvement; likewise, the majority of these studies lack any significant long-term follow-up so it is unclear whether they may be effective in delaying the onset of Alzheimer's disease or other related dementias. . $^{5,59,60}$

As there are several lifestyle factors that promote positive neuroplasticity and cognitive reserve, the literature also shows several lifestyle factors and behaviors that promote negative neuroplasticity and diminish cognitive reserve (Figure 1). Such factors include alcohol and drug abuse, ${ }^{61,62}$ mood disturbances, ${ }^{34}$ poor nutrition, ${ }^{38,39}$ poor health, ${ }^{63}$ and poor education. ${ }^{19-21,33,34} \mathrm{Just}$ as positive health practices are protective of neurological functioning, poor health practices such as substance abuse and chronic stress are not. ${ }^{19-21,33,34}$ Furthermore, the absence of mental stimulation results in low levels of cognitive reserve and an increased vulnerability to cognitive decline and dementia. In fact, studies even suggest that the less formal education one receives, the less one builds up cognitive reserve which makes one more vulnerable to age-related cognitive decline as well as Alzheimer's disease. $^{64}$

\section{Implications for nurses}

Nurses are on the frontlines of health care. With an unprecedented growth in older adults, nurses will see more age-related cognitive decline and dementia in their patients. Although the information provided in this article provides suggestions for mitigating some cognitive loss, nurses are in a position as health educators to also emphasize that cognitive reserve is built up or depleted across the lifespan and that good health promotion practices early on and throughout one's life may impact cognitive function in later life. ${ }^{18}$ Therefore, the information in Figure 1 can be conveyed in health fairs, lectures, and general conversation with others. Thus, when patients are doing something positive for their health, nurses can encourage such behavior by indicating how it may promote successful cognitive aging. Likewise, when patients engage in negative health behaviors, the cognitive consequence in later life may also be used to motivate behavioral change.

\section{Conclusion}

Throughout our lives, we have countless opportunities to enhance our cognitive reserve and mental abilities. Such opportunities allow us not only to possess a better chance at successful cognitive aging, but to engage in life more as well. We interact not only with the environment and the people around us, but with our thoughts and feelings too; and we do so by using our cognitive abilities. Sometimes we forget to talk about cognitive health and mental maintenance because we take our cognitive abilities for granted until they 
are jeopardized, just as we do sometimes with our physical health. As my father has told me time and again, 'If you have your health, you have everything.' This applies to cognitive health too.

\section{Disclosure}

The author reports no conflicts of interest in this work.

\section{References}

1. St John P, Montgomery P. Is subjective memory loss correlated with MMSE scores or dementia? J Geriatr Psychiatry Neurol. 2003;16(2): $80-83$.

2. Vance DE, Ross LA, Downs CA. Self-reported cognitive ability and global cognitive performance in adults with HIV. J Neurosci Nurs. 2008;40(1):6-13.

3. Low LF, Brodaty H, Edwards R, et al. The prevalence of "cognitive impairment no dementia" in community-dwelling elderly: a pilot study. Aust N Z J Psychiatry. 2004;38(9):725-731.

4. McGuire LC, Ford ES, Ajani UA. Cognitive functioning as a predictor of functional disability in later life. Am J Geriatr Psychiatry. 2006; 14(1):36-42.

5. Vandervoort AA. Aging of the human neuromuscular system. Muscle Nerve. 2002;25(1):17-25.

6. Vance DE, Roberson AJ, McGuinness TM, Fazeli PL. How neuroplasticity and cognitive reserve protect cognitive functioning. J Psychosoc Nurs Ment Health Serv. 2010;48(4):23-30.

7. Oosterman JM, Vogels RL, van Harten B, et al. The role of white matter hyperintensities and medial temporal lobe atrophy in age-related executive dysfunctioning. Brain Cogn. 2008;68(2):128-133.

8. Carmichael O, Schwarz C, Drucker D, et al. Alzheimer's Disease Neuroimaging Initiative. Longitudinal changes in white matter disease and cognition in the first year of the Alzheimer disease neuroimaging initiative. Arch Neurol. 2010;67(11):1370-1378

9. Haxaire C, Turpin FR, Potier B, et al. Reversal of age-related oxidative stress prevents hippocampal synaptic plasticity deficits by protecting D-serine-dependent NMDA receptor activation. Aging cell. 2012;11(2): 336-344.

10. Zhao H, Li Q, Zhang Z, Pei X, Wang J, Li Y. Long-term ginsenoside consumption prevents memory loss in aged SAMP8 mice by decreasing oxidative stress and up-regulating the plasticity-related proteins in hippocampus. Brain Res. 2009;1256:111-122.

11. Murphy N, Cowley TR, Blau CW, et al. The fatty acid amide hydrolase inhibitor URB597 exerts anti-inflammatory effects in hippocampus of aged rats and restores an age-related deficit in long-term potentiation J Neuroinflammation. 2012;9(1):79.

12. Peavy GM, Jacobson MW, Salmon DP, et al. The Influence of Chronic Stress on Dementia-related Diagnostic Change in Older Adults. Alzheimer Dis Assoc Disord. 2011. [Epub ahead of print.]

13. Bosco D, Fava A, Plastino M, Montalcini T, Pujia A. Possible implications of insulin resistance and glucose metabolism in Alzheimer's disease pathogenesis. J Cell Mol Med. 2011;15(9):1807-1821.

14. Mattson MP, Gleichmann M, Cheng A. Mitochondria in neuroplasticity and neurological disorders. Neuron. 2008;60(5):748-766.

15. Mattson MP. Glutamate and neurotrophic factors in neuronal plasticity and disease. Ann NY Acad Sci. 2008;1144:97-112.

16. Blau CW, Cowley TR, O'Sullivan J, et al. The age-related deficit in LTP is associated with changes in perfusion and blood-brain barrier permeability. Neurobiol Aging. 2012;33(5):1005. e23-e35.

17. Whalley LJ, Deary IJ, Appleton CL, Starr JM. Cognitive reserve and the neurobiology of cognitive aging. Ageing Res Rev. 2004;3(4):369-382.

18. Vance DE, Graham MA, Fazeli PL, Heaton K, Moneyham L. An overview of nonpathological geroneuropsychology: implications for nursing practice and research. J Neurosci Nurs. 2012;44(1):43-53.
19. Sattler C, Toro P, Schonknecht P, Schröder J. Cognitive activity, education and socioeconomic status as preventive factors for MCI and Alzheimer's disease. Psychiatry Res. 2012;196(1):90-95.

20. Roldan-Tapia L, Garcia J, Canovas R, Leon I. Cognitive reserve, age, and their relation to attentional and executive functions. Appl Neuropsychol. 2012;19(1):2-8.

21. Esiri MM, Chance SA. Cognitive reserve, cortical plasticity and resistance to Alzheimer's disease. Alzheimers Res Ther. 2012;4(2):7.

22. Foley JM, Ettenhofer ML, Kim MS, Behdin N, Castellon SA, Hinkin CH. Cognitive reserve as a protective factor in older HIV-positive patients at risk for cognitive decline. Appl Neuropsychol. 2012;19(1):16-25.

23. Wilson RS, Bennett DA. Cognitive activity and risk of Alzheimer's disease. Curr Dir Psychol Sci. 2003;12(3):87-91.

24. Schweizer TA, Ware J, Fischer CE, Craik FI, Bialystok E. Bilingualism as a contributor to cognitive reserve: Evidence from brain atrophy in Alzheimer's disease. Cortex. 2011. [Epub ahead of print.]

25. Christensen H, Anstey KJ, Parslow RA, Maller J, Mackinnon A, Sachdev P. The brain reserve hypothesis, brain atrophy and aging. Gerontology. 2007;53(2):82-95.

26. Tucker-Drob EM, Johnson KE, Jones RN. The cognitive reserve hypothesis: a longitudinal examination of age-associated declines in reasoning and processing speed. Dev Psychol. 2009;45(2):431-446.

27. Tucker-Drob EM. Differentiation of cognitive abilities across the life span. Dev Psychol. 2009;45(4):1097-1118.

28. Crane PK, Gruhl JC, Erosheva EA, et al. Use of spoken and written Japanese did not protect Japanese-American men from cognitive decline in late life. J Gerontol B Psychol Sci Soc Sci. 2010;65(6):654-666.

29. Mahncke HW, Bronstone A, Merzenich MM. Brain plasticity and functional losses in the aged: Scientific bases for a novel intervention. Prog Brain Res. 2006;157:81-109.

30. Boyke J, Driemeyer J, Gaser C, Buchel C, May A. Training-induced brain structure changes in the elderly. $J$ Neurosci. 2008;28(28):7031-7035.

31. Richards M, Hardy R, Wadsworth ME. Does active leisure protect cognition? Evidence from a national birth cohort. Soc Sci Med. 2003;56(4):785-792.

32. Wilson RS, Scherr PA, Schneider JA, Tang Y, Bennett DA. Relation of cognitive activity to risk of developing Alzheimer disease. Neurology. 2007;69(20):1911-1920.

33. Vance DE, Webb NM, Marceaux JC, Viamonte SM, Foote AW, Ball KK. Mental stimulation, neural plasticity, and aging: directions for nursing research and practice. $J$ Neurosci Nurs. 2008;40(4):241-249.

34. Wilson RS, Arnold SE, Schneider JA, Kelly JF, Tang Y, Bennett DA. Chronic psychological distress and risk of Alzheimer's disease in old age. Neuroepidemiology. 2006;27(3):143-153.

35. Sattler C, Toro P, Schonknecht P, Schroder J. Cognitive activity, education and socioeconomic status as preventive factors for mild cognitive impairment and Alzheimer's disease. Psychiatry Res. 2012; 196(1):90-95.

36. Wilson RS, Bennett DA, Bienias JL, Mendes de Leon CF, Morris MC, Evans DA. Cognitive activity and cognitive decline in a biracial community population. Neurology. 2003;61(6):812-816.

37. Wilson RS, Krueger KR, Arnold SE, et al. Loneliness and risk of Alzheimer disease. Arch Gen Psychiatry. 2007;64(2):234-240.

38. Morris MC, Evans DA, Tangney CC, Bienias JL, Wilson RS. Fish consumption and cognitive decline with age in a large community study. Arch Neurol. Dec 2005;62(12):1849-1853.

39. Staehelin HB. Neuronal protection by bioactive nutrients. Int J Vitam Nutr Res. 2008;78(6):282-285.

40. Vance DE, Heaton K, Eaves Y, Fazeli PL. Sleep and cognition on everyday functioning in older adults: implications for nursing practice and research. $J$ Neurosci Nurs. 2011;43(5):261-271; quiz 272-263.

41. Vance DE, McNees P, Meneses K. Technology, cognitive remediation, and nursing: directions for successful cognitive aging. J Gerontol Nurs. 2009;35(2):50-56.

42. Buchman AS, Boyle PA, Yu L, Shah RC, Wilson RS, Bennett DA. Total daily physical activity and the risk of $\mathrm{AD}$ and cognitive decline in older adults. Neurology. 2012;78(17):1323-1329. 
43. Sturman MT, Morris MC, Mendes de Leon CF, Bienias JL, Wilson RS, Evans DA. Physical activity, cognitive activity, and cognitive decline in a biracial community population. Arch Neurol. 2005;62(11):1750-1754.

44. Vance DE, Wadley VG, Ball KK, Roenker DL, Rizzo M. The effects of physical activity and sedentary behavior on cognitive health in older adults. J Aging Phys Act. 2005;13(3):294-313.

45. Vance DE, Crowe M. A Proposed Model of Neuroplasticity and Cognitive Reserve in Older Adults. Act Adapt Aging. 2006;30(3):61-79.

46. Landau SM, Marks SM, Mormino EC, et al. Association of Lifetime Cognitive Engagement and Low beta-Amyloid Deposition. Arch Neurol. 2012. [Epub ahead of print.]

47. Restak R. Think smart: A neuroscientist's prescription for improving your brain performance. New York, NY: Penguin; 2009.

48. Andrew MK, Rockwood K. Social vulnerability predicts cognitive decline in a prospective cohort of older Canadians. Alzheimers Dement. 2010;6(4):319-325. e1.

49. Wilson RS, Krueger KR, Arnold SE, et al. Loneliness and risk of Alzheimer's disease. Arch Gen Psychiatry. 2007;64(2):234-240.

50. Moyle W, Kellett U, Ballantyne A, Gracia N. Dementia and loneliness: an Australian perspective. J Clin Nurs. 2011;20(9-10):1445-1453.

51. Green AF, Rebok G, Lyketsos CG. Influence of social network characteristics on cognition and functional status with aging. Int $J$ Geriatr Psychiatry. 2008;23(9):972-978.

52. Edwards JD, Wadley VG, Vance DE, Wood K, Roenker DL, Ball KK. The impact of speed of processing training on cognitive and everyday performance. Aging Ment Health. 2005;9(3):262-271.

53. Wadley VG, Benz RL, Ball KK, Roenker DL, Edwards JD, Vance DE. Development and evaluation of home-based speed-of-processing training for older adults. Arch Phys Med Rehabil. 2006;87(6):757-763.

54. Gates NJ, Sachdev PS, Fiatarone Singh MA, Valenzuela M. Cognitive and memory training in adults at risk of dementia: a systematic review. BMC Geriatr. 2011;11:55.
55. Vance DE, Dawson J, Wadley VG, et al. The Accelerate Study: The longitudinal effect of speed of processing training on cognitive performance of older adults. Rehabil Psychol. 2007;51(1):89-96.

56. Vance DE. Speed of processing in older adults: a cognitive overview for nursing. J Neurosci Nurs. 2009;41(6):290-297.

57. Vance DE, Fazeli PL, Ross LA, Wadley VG, Ball KK. Speed of processing training with middle-age and older adults with HIV: A pilot study. J Assoc Nurses AIDS Care. 2012. [Epub ahead of print.]

58. Owen AM, Hampshire A, Grahn JA, et al. Putting brain training to the test. Nature. 2010;465(7299):775-778.

59. Papp KV, Walsh SJ, Snyder PJ. Immediate and delayed effects of cognitive interventions in healthy elderly: a review of current literature and future directions. Alzheimers Dement. 2009;5(1):50-60.

60. Gates NJ, Valenzuela M, Sachdev PS, et al. Study of Mental Activity and Regular Training (SMART) in at risk individuals: a randomised double blind, sham controlled, longitudinal trial. BMC Geriatr. 2011;11:19.

61. Woods SP, Weinborn M, Velnoweth A, Rooney A, Bucks RS. Memory for intentions is uniquely associated with instrumental activities of daily living in healthy older adults. $J$ Int Neuropsychol Soc. 2012;18(1):134-138.

62. Weinborn M, Woods SP, O’Toole S, Kellogg EJ, Moyle J. Prospective memory in substance abusers at treatment entry: associations with education, neuropsychological functioning, and everyday memory lapses. Arch Clin Neuropsychol. 2011;26(8):746-755.

63. Vance D, Larsen KI, Eagerton G, Wright MA. Comorbidities and cognitive functioning: implications for nursing research and practice. J Neurosci Nurs. 2011;43(4):215-224.

64. Roe CM, Mintun MA, D’Angelo G, Xiong C, Grant EA, Morris JC. Alzheimer disease and cognitive reserve: Variation of education effect with carbon 11-labeled Pittsburgh Compound B uptake. Arch Neurol. 2008;65(11):1467-1471.
Nursing: Research and Reviews

\section{Publish your work in this journal}

Nursing: Research and Reviews is an international, peer-reviewed, open access journal publishing original research, reports, reviews and commentaries on all aspects of nursing and patient care. These include patient education and counselling, ethics, management and organizational issues, diagnostics and prescribing, economics and

\section{Dovepress}

resource management, health outcomes, and improving patient safety in all settings. The manuscript management system is completely online and includes a very quick and fair peer-review system. Visit http://www.dovepress.com/testimonials.php to read real quotes from published authors. 